\title{
Place-renewing leadership: trajectories of change for mature manufacturing regions in Europe
}

\author{
D. Bailey, M. Bellandi, A. Caloffi and L. De Propris*
}

\begin{abstract}
The forces of globalisation that are impacting on local economies are both posing a threat to the existing paradigm of competences and routines, yet simultaneously offer opportunities to integrate new knowledge and learning. This is particularly pertinent with respect to Europe's 'mature regions', which are undergoing a major economic restructuring by trying to shift from traditional manufacturing activities to hybrid activities that comprise a combination of manufacturing and a higher component of intangible inputs and related knowledge service activities.
\end{abstract}

The objective of the paper is to discuss the concept of 'place leadership' by looking at how the embedded skills, knowledge and cumulated learning of a place can be used by its institutional infrastructure to identify sustainable growth trajectories. In other words, its aim is to explore how the economic, social, institutional and cultural aspects of places shape the opportunities for upgrading and renovation drawing upon their historical specialisation.

In this context, the paper will compare the experience of the West Midlands in the UK and of Prato in Tuscany and identify good practice and policy recommendations.

Key words: place leadership, public policy, clusters, mature industrial regions, regional economic development.

* Corresponding author: Lisa De Propris; I.de_propris@bham.ac.uk. The authors wish to acknowledge the support of the EU-INTERREG sponsored project 'DISTRICT' and the ESRC under award number RES-000-22-2478. Affiliations: Coventry University Business School, UK; Università degli Studi di Firenze, Italy; Università degli Studi di Firenze, Italy; and Birmingham Business School, UK, respectively. 


\section{Introduction}

Mature manufacturing clusters across many European regions have seen their competitive advantage being eroded as labor intensive activities have moved to lower cost locations and their domestic markets have been flooded with cheap imports. The forces of globalisation and the pace of technological change are impacting on such places of production as never before, posing a threat to their existing paradigm of competences and routines, whilst at the same time offering them opportunities to grasp the benefits of such large scale changes.

However, in order to exploit the opportunities of accessing larger markets, using new or improved technologies, and/or benefiting from external skills, capabilities and knowledge, regions and clusters need to identify and implement appropriate trajectories of change and renewal.

The objective of this paper is to explore the role of 'place leadership' in supporting places of production identifying trajectories that they can follow to remould their competitive advantage and maintain sustainable growth. A large debate on leadership has flourished during the last decade, with important contributions from several disciplines (Stough, 2001, 2003; Gibney and Murie, 2008). A relevant component of this literature has focused on urban renewal strategies, where the object of the analysis is mainly in the urban context, with its socio-economic features and levers for growth (Sullivan and Skelcher, 2002).

Similar to the paper in this volume by MacNeill and Steiner, our attention instead focuses on leadership with respect to the economic and production dimension of places (in line with Stough 2001, 2003) although we will propose a different conceptualisation of places of production and place leadership. Drawing on the international literature, we will discuss leadership in the case of firm clusters and industrial districts. In particular, we will argue that different types of clusters display different forms of leadership both when - pro-actively - supporting the systemic functioning of clusters during incremental changes and when - reactively - acting at times of radical and structural change. Also we will discuss how different forms of leadership vary in the way they coordinate the collective actions of stake-holders influencing the processes of decision-making as well as the outcomes.

The paper will proceed as follows. After a discussion of the source and form of leadership during gradual and conjunctural change (section 2) the paper will introduce the concept of place-renewing leadership (section 3) as a tool for promoting trajectories of change for 'stranded' clusters (section 4). Drawing on the examples of the mechanical cluster of Prato (Italy) and the automotive cluster of the West Midlands (UK), section 5 will discusses the role of organic and place-renewing 
leaderships in identifying, implementing and realising adjustment trajectories for the renewal of mature manufacturing clusters.

\section{Organic leadership in local systems}

In this paper, we consider places of production as local production systems (LPS) where there is a community of people that overlaps with an agglomeration of sector-specialised firms. Prototypical examples of these kinds of LPS are industrial districts (IDs). LPSs are characterised by the following aspects (Bellandi, 2006):

a) the presence of an industry which is embedded in the local fabric of social and civic life, and thereby a community of people that lives and works, with a great deal of persistently overlapping experiences within the same place;

b) An industrial cluster which is at the core of the LPS and which is comprised of several specialised and independent small firms realising complementary and substitute products and services; some of their products are largely sold on external markets, and in a sense define the industrial image and the economic standing of the area;

c) The set of local producers share a relatively high degree of cognitive proximity (a common know how), a set of locally embedded common norms and conventions, an attitude to trust-based reciprocal exchanges, and diffuse attitudes towards co-operative actions among local business and institutional stakeholders (creating a so-called co-operative nexus, Bellandi 2006). Local enterprises are connected by both market and non-market mechanisms.

In general terms, the realisation of the advantages of a well articulated division of labour within a decentralised system of production requires the underlying functioning of key systemic conditions. They allow the alignment of incentives and the satisfactory co-ordination of the specialised contribution of independent producers along the value chain. An internal and pre-defined system of intermediate markets does not cover all firms' needs; indeed product and labour local markets and intra and inter-team exchanges have specific needs. Such idiosyncratic systemic conditions correspond to a complex architecture of specific public or quasi-public goods (within teams, inter teams, cluster-wide, district-wide, and also trans-local). The results of a locally well organised and evolving division of labour are external economies, i.e. economies (partly) external to the single enterprises and internal to the district. Such external economies are the bases for the different processes (including specialisation, learning and creativity) that drive the competitive advantage of industrial districts (Becattini, 1990).

There exists a multiplicity of mechanisms of governance to coordinate the supply of specific public goods. A large body of research on industrial districts has highlighted the role played by private 
stakeholders, such as teams, consortia, and business associations (Dei Ottati, 1991; Brusco, 1999) in initiating collective actions together with public local institutions. The "proactive" nature of these initiatives must be understood in a framework where socio-economic relationships generate shared customs and conventions that grow easily from the accumulation of common experiences and routines within a population of interconnected agents ${ }^{1}$. At times of gradual and conjunctural change, private joint action and public action combine at various levels and degrees, producing a system of local governance able to coordinate and deliver specific public goods in response to specific districts' needs.

More generally, LPSs can also take the form of firm clusters (Bellandi and Sforzi, 2003) and be characterised by many specialised and small-to-medium sized firms; or in other cases, by a dominant local or external large firms. Some may be characterised by a core of manufacturing competencies, others by a core of research and development competencies. What distinguishes such clusters from a casual agglomeration of business activities is that each one is kept together and evolving by some sort of co-operative nexus which connect the local producers. This cooperative nexus may provide the basis for the emergence of "organic" forms of joint action across business and local institutional stakeholders, shaping various forms of governance depending on the nature and power relations of firms: within heterarchical SMEs clusters it may be driven by business associations or local consortia, while in monopsonistic clusters it may be driven by leading entrepreneurs or large firms (main buyers) of the cluster, with a more or less direct involvement of local policy makers (De Propris, 2001).

In LPSs, both industrial districts and clusters, the co-operative nexus connecting the local population of business with institutional stakeholders tends to co-evolve along processes of gradual change that characterise their life cycle. In particular, within a LPS evolving along a path of gradual change, its competitive advantage is reproduced, together with the evolving local division of labour, through various processes of development and variation. In essence, processes of development concern the constitution and evolution of a fabric of local markets for intermediate goods and service; of teams of producers along a value chain; and of public and private organisations. Processes of variation regard instead the dynamics of learning and creative vitality that stem from the dialectic relations between the local, contextual and tacit knowledge and the local and trans-local codified knowledge. At a deeper level, finally, there are processes that reproduce the same socio-economic co-operative nexus, based on the dialectic relation between

\footnotetext{
${ }^{1}$ Following the definition provided by Dei Ottati (1991; 2009), this kind of governance has a "semi-automatic" nature, in so far as it relies on the respect of shared customs and implicit norms of behaviour of an institutionalised nature.
} 
the cohesion and mobility, in the economic and social spheres, of a developing locality open to flows of goods, information, and persons.

The ability of the pro-active local governance to identify, coordinate and deliver initiatives that are the result of a collective system of actions and that will produce a collective benefit, is in our view a unique form of organic leadership. Stough (2001, p.35) defines leadership in the context of regional economic development as the realisation of 'the tendency of a community to collaborate across sectors in a sustained, purposeful manner to enhance the economic performance of its region'. In line with this, but pushing the concept further, we highlight that leadership in this context is required as a form of pro-active collective endeavour to ensure conditions of market creation and to facilitate the systemic functioning of socio-economic-institutional relations.

Organic leadership, therefore, supports the functioning of a LPS along a path where there are gradual and conjunctural changes, through the design and delivery of pro-active initiatives that emerge from the daily inter-action and cooperation within the business and institutional stakeholders embedded in a locality. Organic leadership can assume different features depending on the business and governance architecture of the system: in IDs, where there is a heterarchical and participatory governance, it tends to be more localised, bottom-up and rooted in a context imbued with social capital. On the other hand, in clusters the initiative for joint actions might mirror more or less hierarchical forms of internal governance, to the extent that a large and centralising firm could provide a leadership role, as in the case of a major OEM. ${ }^{2}$

What is also relevant to organic leadership is that, for reasons argued above, it tends to have a very much localised dimension and to have emerged within a local system of production for which it has a very dedicated focus and remit. The geographical scale of its role is, therefore, local because it emerges from the accumulation of the collective interests of a narrow set of stakeholders (i.e it is industry and locality specific), while simultaneously it has to act on specific aspects of the systemic functioning of the cluster or 'district leveraging' and also reconcile private and public interests.

Regional economies, however, can be hit by more radical and structural change; in these circumstances, clusters and districts embedded within such regions have to find a way to devise a form of leadership that can cope with path-breaking adjustments. Linking to the work of Crouch

${ }^{2}$ It is worth clarifying that a firm cluster often coincides with a "locality" which might identify itself with an administrative area, e.g. a municipality, a county, or a region. The cluster may be seen just as the result of converging external forces, in particular strategic and market forces. In this case, the emergence of organic forms of leadership may be hampered by the absence of a common ground of knowledge and institutions, dedicated needs and perceptions shared by the local actors. 
and Farrell (2002) in revisiting the very concept of path-dependency, they note that the concept itself "implies the existence of alternative paths of development... which may be 'rediscovered when actors face a changed environment which makes new demands" and highlight the "incongruities, incoherence, and within-system diversities" that "very frequently provide the means through which actors - whether firms, policy entrepreneurs or others - may seek to tackle new exigencies". As they note, changing paths is costly but not impossible. Our point is that the form of leadership required to explore such "alternative paths" that co-exist alongside the dominant one and overcome potentially costly barriers to such path-change is of a very different form to that of organic leadership.

\section{3. 'Place-Renewing Leadership' in a context of radical change}

It has become well accepted in the literature that the competitiveness and wealth of regions rest on the presence of competitive LPSs. The latter have, since the 1980s, driven processes of innovation and growth drawing on embedded regional specialisations especially in manufacturing sectors. However, theories of cluster life-cycle (Swann 1998) suggest that after a period of growth and expansion, clusters tend to reach a stage of maturity, where they appear to be well established in their markets, with strong and solid competences that have diversified around a core specialisation and well-functioning mechanisms of learning and innovation within a particular product or technology. In this position we find many manufacturing clusters across European regions. They have developed over time competitive advantages that stem from their cumulated knowledge and the systemic nature of their value chain and innovation processes.

Such advantages have been strongly challenged by the presence of external and related internal radical changes. The most relevant exogenous shocks have been linked to the pace and the nature of technological change, and to the scale and penetration of globalisation. ${ }^{3}$ Indeed the fast pace of technological upgrading and the extent of changes in the underlying platforms, are forcing district and cluster firms to access and absorb new and codified knowledge that needs to be embodied in their set of existing know-how and competences. On the other hand, globalisation has changed the geographical scale, the intensity, the flows and the content of exchanges, which have become multi-geometry -spreading from local to global and back again - and have included goods, services, people and more crucially knowledge and technology. In particular, the organisation of production that in the post-Fordist period has been fundamentally stage-specialised, integrated and co-located has changed due to the 'opportunities' or 'pressures' of globalisation. The global

\footnotetext{
${ }^{3}$ See for example Bailey (2008) on globalisation and technological change the auto sector and implications for the West Midlands auto cluster.
} 
organisation of production activities has coincided with a new and distinctive phenomenon that has 'de-territorialised' in some sense production activities (Scholte 2000). ${ }^{4}$ These global production networks mirror a web of market and ownership relations that combines flexible specialisation throughout the value chain, but where functions are located in different places depending on the contribution that they can make to the overall division of labour. Both globalisation and technological change can inflict radical and structural changes to local systems, which in the absence of a strategic form of leadership can cause a fatal decline.

The major effects of these external shocks have been twofold. On the one hand, there has been a process of 'manufacturing hollowing out' that has followed the tendency of firms to shift or relocate labour intensive activities away from so-called traditional manufacturing regions in search of cost reductions. ${ }^{5}$ The consequence of this production re-location has been to alter the systemic functioning of the division of labour in the place of origin. Indeed, when firms close down to relocate their functions abroad (especially for labour intensive tasks), this has implications for the set of competences and skills comprised within the systemic value chain. An impoverishment of local competences and skills can cause a dismantling of the local division of labour where gaps emerge, as well as a thinning of local socio-economic networking. On the other hand, the need to exploit the opportunities of globalisation has led to an 'hierarchisation' of the industrial structure around one or a few leading firms, thus totally changing the balance of power and competences within the system of firms, especially those characterised by small and medium-sized ones.

Other radical and structural changes can be triggered by technological changes which LPSs are unable or unwilling to absorb incrementally because of the scale and pace of change. The result can be fatal knowledge path-dependency and technological lock-in, which in turn may lead to an erosion of local mechanisms of learning and innovation.

In summary, such exogenous shocks can be argued to cause internal radical and structural changes that can impact on firms' and systems' immediate survival prospects. We would argue that these changes may weaken or even hollow-out the basis of the existing form of organic leadership which becomes unable to exert a form of pro-active support to the local industry. There are a number of reasons for this. Firstly, being a direct expression of the endogenous forces shaping the local industry, organic leadership may be affected by the same myopia, pathdependence, lock-in mechanisms as individual firms. Moreover, institutional lock-in may crystallise both the local 'rules of the game' and the local leadership within outdated forms of collective

\footnotetext{
${ }^{4}$ For an introduction to the vast literature on global value chains, see Dicken (2006).

${ }^{5}$ See for instance the essays in Bailey et al 2007 on the hollowing-out phenomenon in Japan.
} 
response which are inappropriate to face the current needs of adaptation and change. Secondly, the co-operative nexus binding local producers together may be undermined by changes occurring within the socio-economic sphere of the local system (Dei Ottati, 2009).

At times of radical change, new forms of leadership are hence needed in order to identify possible trajectories for the survival and growth of LPSs and to promote the adaptation of LPSs to a (partly) new architecture of systemic conditions, including new or renewed specific public goods. This new form of leadership does not have to be the expression of a top-down approach to policy, since as discussed in the previous section, collective initiatives need to be firmly rooted within the local industry (and see MacNeill and Steiner on 'distributed' leadership in this volume). Nor are they purely bottom-up strategies, since (as will be discussed in the following section) they require forms of strategies that go beyond the purely local sphere. 'Place-renewing leadership' is thus a form of public-private strategic leadership that empowers institutional or social forms of governance to absorb and adjust (pro-actively and re-actively) to path breaking economic change. They are required in order to support the development and the implementation of strategic policies in the face of crises that cannot be effectively addressed by existing governance architectures (Stough, 2003). Place-renewing leadership tends to cover a regional rather than a local space in order to allow for the strategic coordination of trans-systemic synergies. Indeed it brings together the bottom-up design and implementation of collective initiatives that support the local systems whilst enabling such initiatives to benefit from the sectoral diversification of a regional economy through sector cross-fertilisation.

The specific tasks that a place-renewing leadership should accomplish vary according to the specific trajectory of cluster/district renewal and change. They will be detailed in the next section.

\section{Place-Renewing Trajectories}

The emergence of external shocks that induce such radical economic change and the need for 'place-renewing leadership' raises key issues regarding what trajectories traditional manufacturing clusters and districts could follow to remould their competitive advantage and maintain / re-attain sustainable growth. We would argue that in order to embark on such trajectories in such a situation of radical external shocks, strategic place-renewing leadership would be required.

One key issue is to consider the analysis of LPSs' trajectories not simply in the context of a locally bound system, but rather considering it as part, first of all, of a more diversified regional economy and even more broadly within the global supply chain context. Such trajectories are designed to 
enable clusters and districts to 'leap' from situations of inertia and technology obsolescence onto path(s) of upgrading and renewal.

The challenges that LPSs face and their responses have engaged the academic and policy debate: Humphrey and Schmitz (2002) refer to cluster upgrading to describe processes of innovation adoption that include product and process; Stimson et al (2002) suggest that rapid and continuous change requires 'regional re-engineering' which chances the learning infrastructure, processes and capabilities; Bailey and MacNeill (2008) describes processes of regional diversification to steer stagnating or declining localities towards sustainability.

We identify three possible trajectories (DISTRICT, 2008) to renew, reposition and strengthen LPSs:

1. Entering and securing high-value added market segments. This trajectory would imply strategies to support firms in trying to move away from mass production and price competition, in order to identify niche markets for high value added, high design, and highly creative and often customer-oriented goods and services. As a strategy, product differentiation involves a new conceptualisation of what goods and services represent, in the sense that the symbolic and aesthetic value of the goods are changing in their perception to consumers and, upstream, the modes of production. The literature has converged towards recognising the role of knowledge-intensive business services (The Work Foundation, 2009) in changing the nature of manufacturing activities by providing intangible content and ultimately value creation. The latter is therefore reliant to an extent on soft forms of innovation (Stoneman 2007), defined as innovation in either goods or services that primarily impact upon sensory perception and aesthetic, rather than functional, appeal. Higher value-added production usually also tagrets the top end of the market and can benefit from less price elastic demand, but at the same time may risk being more cyclical in nature (witness the luxury auto market). This trajectory would be suitable for mature clusters in jewellery, clothing, leather, textiles, ceramic, glass, as well as in the automotive sector for the luxury segments.

Product upgrading might go in parallel with changes linked to process innovation; for instance, as clusters absorb and process high knowledge-intensive functions through their internal value chain, they renew not only the stock and the flow of embedded competences but also the composition of the process of value creation. Process and organisational innovation tend therefore to lead to a form of systemic innovation, whereby the system of internal intermediate markets change to accommodate the new functions together with the circuits of knowledge. 
These two elements often go together. When companies move upmarket, product design and process innovation are crucial in (a) stripping out costs and (b) building in quality enhancements for consumers. An example is the last generation Jaguar $\mathrm{XJ}$ model, which is made of aluminium, and is half the weight of the previous model: this car is both 'high tech' and the output of a different production technology. It has also involved a change in the organisation of production, with employees of another firm, StadCo, working on the XJ production line at the Jaguar plant. The next generation is likely to feature more weight saving components as well as an electric-powered version.

2. Cross-sector fertilisation. This second trajectory implies a broader view of the renewing opportunities of a cluster, since it entails the opportunity for the cluster to search for market opportunities beyond its usual final customers. In particular, the diversification of the cluster would mean identifying novel applications as intermediate goods to high-tech sectors. Examples of this in the West Midlands have been the opening of the ceramics cluster to use part of its competences to produce highly specific ceramic components for engines and aerospace; in the same way, car components have taken the opportunity to shift from supplying the auto sector only to open up to medical devices. Along this trajectory, clusters reposition certain internal resources and competences from the margins to the core of their competitive advantage, and apply them to supply new and potentially very different markets. In particular, along this second trajectory the cluster needs to be able to look beyond its well known system of internal circuits of goods, services and knowledge and to identify synergies across related sectors. This cross-sector fertilisation could in theory be an extremely difficult thing for the cluster to do since it implies opening the network of socio-economic relationships to parties outside the locality, and related to this, a re-organisation of its internal knowledge flows and relations.

3. Re-positioning in the global value chain. This third trajectory is interrelated to the opportunity of firms to open up to new sectors or new market segments, and the positioning of their production activity in the global supply chain. A cluster's re-positioning within the global supply chain would imply a shift in its core competences/activities. International linkages might be the drivers or the outcome of core-shifting and core-upgrading strategies. As the cluster re-focuses its core competences, it tries to re-new its competitive advantages and to identify possible survival paths. In this context, we might see the cluster re-designing the geometry of the complementary functions comprised in its value chain, whilst identifying and securing a niche role in the global value chain. Along this trajectory, clusters are not only pushed to engage more widely within a regional economy, but to completely open intermediary markets to an international demand. 
These adjustment trajectories are in summary meant to move manufacturing clusters and districts towards knowledge-intensive activities. These corrections require a re-combination of embeddedness and openness and a re-combination of soft and hard innovation. Key to these processes we envisage two set of enablers: multi-geometry networking and reliance on soft and hard innovation.

Networking is the core functioning mechanism for all forms of LPSs since it coincides with the 'plumbing system' through with goods, services and knowledge is exchanged, as well as providing channels for social interaction, stakeholders engagement in collective action, and cooperation relations. The modular and dis-integrated organisation of production within LPSs depends on the input-output exchanges between firms specialised along the value chain of a particular production. It is well known that such firm-networking is also a crucial channel for the adoption of new innovation (hard and soft) and for joint innovation. Such systemic networking needs to be extended to a trans-local scale or even internationally, if the full benefits of joint innovation and knowledge sourcing are to be reaped. On the other hand, soft and hard innovation offers firms the opportunity to undertake product differentiation and diversification. Hard innovation is R\&D related and tends to be associated with 'pure' technological novelties in the form of radical or incremental innovations; whereas, more recently the flourishing debate on creativity has introduced the concept of soft innovation (Stoneman, 2007) to describe radical or incremental novelties that re-define the aesthetic or functional value goods.

Table 1 below describes for each of the three trajectories, how networking and innovation can be enablers of renewing change, and how place-renewing leadership can act to activate the enablers in order to move and sustain localities on the appropriate adjustment trajectory. Section 5 will present two case studies: one describing the attempt of the textile district in Prato (Tuscany) to reposition itself in the global value chain; and West Midlands (UK) regional adjustment in the wake of the contraction of the automotive cluster via aross-sector fertilisation strategy. 
Table 1

\begin{tabular}{|c|c|c|}
\hline Trajectories & Enablers & $\begin{array}{c}\text { Place-renewing leadership } \\
\text { Tasks }\end{array}$ \\
\hline $\begin{array}{l}\text { Entering and } \\
\text { securing high-value } \\
\text { added market } \\
\text { segments }\end{array}$ & $\begin{array}{l}\text { Networking } \\
\text { - Knowledge sourcing through local and trans- } \\
\text { local partnerships } \\
\text { - Joint cooperation with local education or } \\
\text { innovation capacity to adopt product and } \\
\text { process innovation } \\
\text { Innovation } \\
\text { - Adoption of soft innovation, e.g. design, } \\
\text { creativity branding } \\
\text { - For some industries, the aesthetic value of } \\
\text { innovations is related to hard innovation } \\
\text { especially in relation to new materials or } \\
\text { processes } \\
\text { - Adoption of new design, ideas, technologies } \\
\text { that combined with the existing ones can } \\
\text { renew products and processes } \\
\text { - Development of an internal innovation } \\
\text { capability at the firm level }\end{array}$ & $\begin{array}{l}\text { - Leadership has the ability to carry out a } \\
\text { 'birds' eye' appraisal of current and } \\
\text { imminent trends in view of sector } \\
\text { differentiation } \\
\text { - Inform of sector trends and raise } \\
\text { awareness of firms' innovation gap and } \\
\text { need for change } \\
\text { - Encourage and support links with } \\
\text { universities, innovation capacity and } \\
\text { creativity capacity in the region } \\
\text { - Encourage firms' HR knowledge upgrading } \\
\text { - Support firms' foreign exposure (trade } \\
\text { - Sairs); } \\
\text { - Support firms' international networking (EU } \\
\text { industry schemes, export and marketing } \\
\text { advice and guidance) to identify niche } \\
\text { markets and innovative partnerships } \\
\text { - Support firms' penetration of top end final } \\
\text { markets (domestic and overseas) }\end{array}$ \\
\hline $\begin{array}{l}\text { Cross-sector } \\
\text { fertilisation }\end{array}$ & $\begin{array}{l}\text { Networking } \\
\text { - Regional or inter-regional networking to } \\
\text { identify sector diversification opportunities } \\
\text { (i.e. intermediate markets along the value } \\
\text { chain) } \\
\text { - Links with universities and innovation } \\
\text { capacity to support identify opportunities for } \\
\text { sector diversification } \\
\text { Innovation } \\
\text { - Adoption of new technology and knowledge, } \\
\text { and their adaptation in conjunction with the } \\
\text { existing ones to exploit opportunities for } \\
\text { market diversification } \\
\text { - Both soft and hard innovation is involved } \\
\text { - Product and process innovation jointly } \\
\text { between buyers and suppliers cooperating } \\
\text { along the value chain }\end{array}$ & $\begin{array}{l}\text { - Leadership has the ability to carry out a } \\
\text { 'birds' eye' appraisal of current and } \\
\text { imminent trends of the sectors in the region } \\
\text { - Identify opportunities for sectors' synergies } \\
\text { and cross-fertilisation (thanks to an } \\
\text { understanding of the suite of competences } \\
\text { in the region) } \\
\text { - Inform stakeholders of the opportunities of } \\
\text { cross-sector fertilisation } \\
\text { - Liaise with businesses, universities and } \\
\text { public/private institutions to maximise } \\
\text { cross-sector synergies } \\
\text { - Firm match-making to set up new } \\
\text { partnerships across related industries in } \\
\text { view of identify new cross-sectoral links }\end{array}$ \\
\hline $\begin{array}{l}\text { Re-positioning in } \\
\text { the global value } \\
\text { chain }\end{array}$ & $\begin{array}{l}\text { Networking } \\
\text { - National and global networking to exploit } \\
\text { opportunities linked to global value chains in } \\
\text { higher-value added segments through } \\
\text { product diversification and differentiation } \\
\text { - Opening to GVA } \\
\text { Innovation } \\
\text { - Shift of core competences from low value } \\
\text { added functions to high tech ones (e.g. from } \\
\text { textiles to textile machinery or from textiles } \\
\text { to clothing) } \\
\text { - Effort in hard innovation } \\
\text { - Adoption of and adaptation to new } \\
\text { knowledge and technology }\end{array}$ & $\begin{array}{l}\text { - Leadership has the ability to carry out a } \\
\text { 'birds' eye' appraisal of current and } \\
\text { imminent trends of the sectors in the region } \\
\text { - Identify opportunities for sectors' } \\
\text { internationalisation strategies through entry } \\
\text { in GVA } \\
\text { - Inform stakeholders of the opportunities of } \\
\text { cross-sector fertilisation } \\
\text { - Support firms' international networking to } \\
\text { identify niche markets and innovative } \\
\text { partnerships }\end{array}$ \\
\hline
\end{tabular}




\section{Case Studies}

\subsection{The Prato Textile Machinery District}

The district of Prato is one of the most famous textile industrial districts in Italy. ${ }^{6}$ The mechanical cluster localised in the district emerged during the ' $60 \mathrm{~s}$, nurtured by the presence of a growing local demand for textile machineries which seeded a lively "local laboratory" for designing, manufacturing and testing new products. ${ }^{7}$ Building on this base, a set of local SMEs have gradually evolved from performing servicing activities for the textile enterprises localised within the district, to the manufacturing of textile machineries, ${ }^{8}$ both for local and extra-local markets. ${ }^{9}$ Private joint action by teams, consortia, and business associations has supported the development of the cluster, promoting a further enlargement of markets and export activities (Dei Ottati, 2002). Thanks to the financial support of the local government, a special section of the local vocational school has been created in the district, in order to provide focused training for workers and managers. ${ }^{10}$ Moreover, a team of private entrepreneurs, in collaboration with the local government, has promoted the creation of other specific public goods, such as two new industrial zones and a district logistic platform.

After several decades of growth, the development of the cluster is nowadays challenged by two main phenomena: the progressive crisis of the textile producers of the district and the growing competition from Asian producers of textile machineries. These two phenomena have combined in various ways with the emergence of some weaknesses of the local industry and of the organic forms of local leadership. Indeed, it is worth noting that the number of firms located in the textile district has fallen from 7753 in 1995 to 4819 in 2005 (a contraction of nearly $40 \%$ in ten years). ${ }^{11}$ For the mechanical producers, the shrinking of the local textile manufacturing base has not simply resulted in a reduction in the number of possible (or effective) clients, but it has also gradually

\footnotetext{
${ }^{6}$ Among the large number of contributions on the topic, see: Becattini (1997), Lazzeretti and Storai (2001), Dei Ottati (2002).

7 This analysis of the Prato mechanical cluster draws on (2007) which included fieldwork study on the mechanical cluster of Prato, with direct interviews with the mechanical enterprises of the cluster, local policy makers and expert analysts. The field work was performed during the period April-June 2007.

${ }^{8}$ Initially, a set of local SMEs operated as business agents for the world-famous European producers of textile machineries (mainly Swiss or German producers), performing also servicing activities for their textile clients localised within the district. These local firms found a growing local market for their services as the production realised by the textile firms continued to growth for decades. Most important, they have been embedded within an innovative market since the textile firms continuously introduced variations within the range of their products and required continuous adaptations in the machinery they have installed.

${ }_{9}$ Until 2004, Italy ranked first in world trade of textile machineries (Acimit, 2005).

${ }^{10}$ The local Industrial Technical Institute specialised in textiles was founded in 1886 thanks to the support of the Prato City Council. The special division specilaised in "mechanics" was created at the beginning of the '70s.

${ }^{11}$ Data Movimprese-Unioncamere (http://www.infocamere.it/movimprese.htm) referring to the Province of Prato.
} 
hollowed-out their innovative capacity. The exchanges with extra-local clients (mainly Asian clients, but also South American and East-European) has never fully replaced this loss, mostly because for the SMEs of the district the direct management of international markets (which can provide the local enterprises with crucial pipelines of knowledge and competencies) have generally proved to be difficult.

As for the international competition, during the last decade the mechanical enterprises of the district are increasingly pressed both by price competition coming from Asian producers and by high quality competition coming from European producers that have tried to renew their products. As a result, since 2000 the mechanical component has started to shrink, with a gradual reduction in the number of the local mechanical enterprises (from 441 in 2001 to 385 in 2007) and of their employees (-20\% over the same period).

In order to react to the crisis, a set of local enterprises have experimented with new strategies. Some of them have tried to shift to high-value added market segments (e.g. moving towards the production of specialised machineries for cashmere), others have tried to re-position their activity along the global value chain (e.g. moving towards the direct management of the final markets and increasing the service content of their products) while others have explored new markets, trying to move towards the production of machineries for special kinds of technical textiles (e.g. special textiles for the construction or the automotive industry).

However, in order to transform a small set of individual reactions into new strategies for supporting cluster trajectories of change, the cluster actors need to develop new specialised goods, and to adapt the set of specific public goods upon which their competitiveness has been grounded. The direct management of international value chains, the product upgrading of the local industry, the full realisation of cross fertilization processes require the development of new knowledge and capabilities which are not automatically produced and managed by the organic working of the local leadership mechanisms. Moreover, the full deployment of place-renewing trajectories requires the mobilisation of long term, vision-led agendas which may bring novelties and ruptures to the existing mechanisms of local governance.

In the mechanical cluster of Prato, the traditional forms of leadership supporting the local industry (e.g. sector-based consortia, local associations) seem to have been unable to support this fundamental change. At the same time, new forms of place-renewing leadership appear to have to been created; in particular, a set of local and regional public actors has tried to identify new development goals for the district as a whole. The local government has promoted the creation of a strategic plan for the city aimed at driving the growth of the local district in the current scenario of 
urban and industrial transformation. ${ }^{12}$ A strong support for the renewal of the district has also come from the provincial and regional governments which have funded the creation of a local exhibition centre and a research centre focussed on innovative textiles and machineries.

However, these new forms of leadership are still in their experimental phase, and they run the risk of being perceived as mere top-down development strategies, especially in a district where the associations representing very localised interests and needs are well-settled as they have emerged spontaneously to interpret collective actions, in the same way as they tend to rely on a local repository of norms and conventions. In this context, an appropriate and accepted placerenewing form of leadership struggles to be established and to develop. To do so, it would need to stem from new participatory governance processes and tools as well as to build a shared vision of local development goals.

\subsection{The West Midlands Auto Cluster}

This case study looks at the restructuring in the auto sector and its impact on the West Midlands, notably the successive crises at the car maker MG-Rover. Whilst the firm's eventual collapse in 2005 was a substantial shock to the West Midlands economy, the impact was been much less than was anticipated when the firm was first threatened with closure in 2000 at the time of its break-up and sale by BMW. Back in 2000, the then Chair of the Regional Development Agency, Alex Stephenson, stated that "we looked over the edge and didn't like what we saw" (Bailey, 2000). As a result, it was the regional tier of governance - through the Regional Development Agency (RDA) and Government Office of the West Midlands - which secured from central government funding for a package of measures to support businesses most dependent on MG-Rover and, at the same time, address long-term weaknesses in the regional economy. This came after central government saw its role as finished with the sale of Rover to Phoenix; it was very much the regional tier which took the lead in identifying the problems in the supply chain locally as well as the fragility of the MG Rover position and pressing for a support package.

Thus the Rover Task Force Report (RTF, 2000) focused on the inter-linked themes of modernisation, diversification, and regeneration. The RTF also recognised that over-reliance on the automotive sector, and MG-Rover in particular, plus the concentration in low value-added 'metal bashing', and a lack of a significant involvement in higher value-added areas as electronics, communications or fuel saving technologies, meant the region was particularly vulnerable given the

\footnotetext{
${ }^{12}$ Both the city strategic plan and the city strategic planning process are documented in the web page of the Municipality of Prato: http://www.comune.prato.it/governo/piano/htm/ps.htm.
} 
global changes taking place in the industry. While Modernisation included a number of linked initiatives to improve competitiveness, through increased productivity, the new Diversification programme sought to help suppliers diversify away from Rover, and from automotive in general, by encouraging the application of engineering skills to other industries such as medical technologies. Given the on-going concern about Rover's long term prospects, RTF1 also initiated spatial targeting via corridors of regeneration. The RTF1 Final Report identified three areas for in-depth study of their growth potential as "high-tech corridors". Linking these area based initiatives with the clusters would indeed have provided a genuine innovation but for the most part the RDA was unable to achieve this except in the regeneration of the unused areas of the Longbridge site (ibid).

The actions taken to address the on-going MG-Rover difficulties from 2000 to 2005 can nevertheless be described as a successful example of crisis management, with leadership being provided by the RDA. There were clear benefits in addressing the short-term market needs of local supply companies and the unemployment that resulted from the final closure of the company. In policy terms the crisis prompted an acceleration of regional-level initiatives which have undoubtedly brought benefits to the local economy. Firstly, the modernisation and diversification agendas recognised the need to shift suppliers away from dependence on MG-Rover; in so doing, they assisted firms looking for new markets and applications and contributed to the $10,000-12,000$ jobs 'saved' over 2000 to 2005 (Bailey and MacNeill, 2008). Secondly, the MG-Rover crises kickstarted a regeneration agenda and the development of spatial targeted policies to develop new technologies centred on the corridors, which in two cases, at least, have begun to draw in other key local organisations such as universities. More broadly, the crisis highlighted the need to move the auto 'cluster' towards high-performance and prestige markets, to diversify the economic base away from dependence on the sector, as well as the need to overcome a defensive style of capitalism amongst small firms that mitigates against co-operation and the benefits of innovative activity therein (see De Propris, 2000).

Whilst AWM has faced a number of difficulties in dealing with the MG-Rover situation (Bailey and MacNeill, 2008), as Fuller et al (2002) note, Rover was "very important in fostering joint strategy making and action across the region" (ibid). Given its difficulties, it was not surprising that the RDA had to turn to established groups and projects for delivery of the RTF measures. Indeed, much of the direct support to manufacturing companies was based upon the existing, and 'Rovercentric' initiative, Accelerate, which had been developed as a process-oriented supplier improvement (short-term reduction in supply costs) programme - as sought by the region's major companies and, in particular, MG-Rover itself. Thus, although the RTF funds provided valuable direct support to individual companies, little was done to address the region's on-going skills shortages (Tilson, 1997) or to improve the technological base. 
A regional cluster policy has the potential to take a holistic approach focused on 'soft infrastructure' and competence building (Lundequist and Power, 2002). Implemented in this way, the cluster approach has the potential to increase the regional technology base and develop ties between footloose transnational firms and the locality (see Malecki, 1997). However, by concentrating support through the Accelerate programme, rather than through the developing cluster policy, the RTF made relatively little progress in this direction. It is clear however that providing the 'soft support' associated with the learning economy represents a major challenge (see Storper, 1997), not least for an RDA lacking power and resources over many of the areas in question.

Although unable to mobilise forces in time to address these deeper structural issues, AWM did at least recognise the need for a broad approach. Thus during the period between the two MG Rover crises a considerable investment in new technology was made at Warwick Manufacturing Group where more than $£ 30$ was made available by a combination of the DTI (BERR) and AWM for the PARD ${ }^{13}$ Programme (Bailey and MacNeill, 2008). This encompassed a range of high tech projects, including advanced materials (formability of composites and alloys of aluminum and steel), joining and assembly technologies, electronics (testing rather than development) and hybrid systems, and was an attempt to both 'kick-start' new technology and to 'embed' Ford in the region. Although a review of PARD has yet to be undertaken it is apparent that it has achieved many of its short term goals. However, longer term sustainability is doubtful without the addition of further public funding. In addition the objective of keeping Ford in the region was unrealistic given the scale of the parent company's losses, with the firm selling off both Aston Martin and Jaguar Land Rover.

\section{Concluding remarks}

The paper thus examines the role of organic and place-renewing leaderships in identifying, implementing and realising adjustment trajectories for the renewal of mature manufacturing clusters. Parallel to the piece by MacNeill and Steiner in this volume, we focus on 'leadership' with respect to the economic and production dimension of places (in line with Stough 2001, 2003) although here we have proposed a different conceptualisation of places of production and place leadership. We suggest that different types of clusters display different forms of leadership both when - pro-actively - supporting the systemic functioning of clusters during incremental changes and when - reactively - acting at times of radical and structural change. In so doing we consider how different forms of leadership vary in the way they coordinate the collective actions of stake-

\footnotetext{
${ }^{13}$ PARD stood for Premier Automotive Research and Development and was set up at a time when Ford had brought its luxury brands (Volvo, Lincoln, Jaguar, Land Rover and Aston Martin) under a single organisation. The company was broken into separate parts in 2002 following concerns about the effect on Ford's 'home' luxury brand, Lincoln.
} 
holders influencing the processes of decision-making as well as the outcomes. Two case studies of mature manufacturing regions are used to highlight the work of Crouch and Farrell (2002) in revisiting the very concept of path-dependency. The latter note that the very concept of pathdependency implies the existence of alternative paths of development which may be "rediscovered when actors face a changed environment which makes new demands" and highlight the "incongruities, incoherence, and within-system diversities" that "very frequently provide the means through which actors - whether firms, policy entrepreneurs or others - may seek to tackle new exigencies". As they note, changing paths is costly but not impossible. Our point is that the form of leadership required to explore such "alternative paths" that co-exist alongside the dominant one and overcome potentially costly barriers to such path-change is of a very different form to that of organic leadership. The cases highlight both successes and failures of leadership in attempting to change paths.

\section{References}

Bailey, D. (2000). The Advantage is About Keeping a Region out of Trouble, Parliamentary Brief, 2000, Vol.6, No.7.

Bailey, D. (2008), Globalisation and Restructuring in the Auto Industry: The Impact on the West Midlands Auto Cluster, Strategic Change, Vol.16, 2007, 137-144.

Bailey, D, D Coffey and P Tomlinson. (2007), ed.s, Crisis or Recovery in Japan? State and Industrial Economy. Cheltenham: Edward Elgar.

Bailey, D and S MacNeill. (2008), The Rover Task Force: A Case Study in Proactive and Reactive Policy Intervention? Regional Science Policy and Practice. Vol.1, Iss.1, 2008, 1-16.

Becattini G. (1990) The Marshallian Industrial District as a Socio-economic Notion, in F. Pyke, G. Becattini and W. Sengenberger (Eds) Industrial District and Inter-firm Cooperation, IILS:Geneva, pp. 37-51.

Bellandi M. and Sforzi F. (2003) The Multiple Path of Local Development, in G. Becattini, M. Bellandi, G. Dei Ottati and F. Sforzi (Eds) From Industrial Districts to Local Development, Edward Elgar: Cheltenham, pp.210-226.

Bellandi M. (2006), A perspective on clusters, localities and specific public goods, in C. Pitelis, R. Sugden and J. Wilson (eds), Clusters and globalisation. Edward Elgar, Cheltenham, pp. 96-113.

Bellandi M. (2003), Industrial clusters and districts in the new economy: some perspectives and cases, in Sugden R., Hartung Cheng, R, Meadows R (eds) Urban and Regional Prosperity in a Globalized, New economy, Edward Elgar, Cheltenham, pp.196-222.

Brusco S. (1999), The rules of the game in industrial districts, in A. Grandori (ed.), Interfirm networks. Organization and industrial competitiveness, Routledge, London, pp.17-40.

Crouch, C. and Farrell, H. (2002), Breaking the path of institutional development? Alternatives to the New Determinism, Discussion Paper, 02/5, Max Planck Institute for the Study of Societies. 
De Propris, L. (2000) Innovation and Inter-Firm Cooperation: the Case of the West Midlands, Economics of Innovation and New Technology, Vol.9.

Dei Ottati G. (1991), The economic bases of diffuse industrialization, International Studies of Management \& Organization, vol. 21, n.1, pp-53-74.

Dei Ottati, G. (2009), Semi-Automatic and Deliberate Actions in the Evolution of Industrial Districts, in G. Becattini, M. Bellandi and L.De Propris (Eds.) Handbook of Industrial Districts, Edward Elgar, Cheltenham.

DISTRICT (2008) A Framework in the Analysis of Clusters Trajectories (2008) The DISTRICT Regional Framework at Work: Innovation Pathways and Knowledge Economy, INTERREG Regional Framework Operation Project DISTRICT, DG Regional Policy, European Commission.

Fuller, C, R J Bennett and M Ramsden. (2002) The Economic Development Role of English RDAs: The Need for Greater Discretionary Power, Regional Studies, Vol 36, No 4.

Gibney, J. And Murie A. (2008) Toward a 'New' Strategic Leadership of Place for the Knowledgebased Economy, mineo School of Public Policy, University of Birmingham, June. University of Birmingham.

Lundequist, P and D Power. (2002) Putting Porter into Practice? Practices of Regional Cluster Building: Evidence from Sweden, European Planning Studies, Vol.10, No.6.

Malecki, E J. (1997) Technology and Economic Development: The Dynamics of Local, Regional and National Competitiveness. Longman.

PICTURE (2007) A Framework for the Analysis of Cluster Trajectories Report to Steering Committee of PICTURE, INTERREG Regional Framework Operation Project DISTRICT, DG Regional Policy, European Commission.

Scholte J.A. (2000) Globalization: A Critical Introduction. Basingstoke/New York

Stimson, R.J, R.R. Stough and M. Salazar (2003) Leadership and institutional factors in endogenous regional economic development, Investigaciones Regionales, No. 7, pp. 23-52.

Stoneman P. (2007) An introduction to the definition and measurement of soft innovation, NESTA, Working Paper, October.

Storper, M. (1997) The Regional World: Territorial Development in a Global Economy. New York: Guilford.

Stough, R.R. (2001) Endogenous Growth Theory and the Role of Institutions in Regional Economic Development, in Z. Acs et al (Eds) The Emergence of the Knowledge Economy: A Regional Perspectives, Springer, Berlin.

Stough R.R. (2003) The Strategic Management of Places and Policy, The Annals of Regional Schience, 179-201.

Sullivan, H. and Skelcher, C. (2002) Working across Boundaries. Collaboration in Public Services. Basingstoke: Palgrave Macmillan.

Swann G. M. P. (1998) Towards a model of clustering on high-technology industries, in Swann G. M. P., Prevezer M. and Stout D. (Eds) The Dynamics of Industrial Clustering. Oxford University Press, Oxford. 
Bailey, Bellandi, Caloffi \& De Propris final author version for Policy Studies

Tilson, B. (1997) Survey of Firms in the Automotive Components Sector in the West Midlands Region. Final Report for the West Midlands Development Agency. Birmingham: Centre for Urban and Regional Studies, The University of Birmingham.

The Work Foundation. 2009. Manufacturing and the Knowledge Economy. London: The Knowledge Economy. 